\title{
Citing Resources in Scientific Research
}

\section{Richard Boudreau}

Attorney at Law \& Faculty, Bioethics Institute, Loyola Marymount University, CA, USA

"Corresponding author: Richard Boudreau, Attorney at Law \& Faculty, Bioethics Institute, Loyola Marymount University, CA, USA, Tel: 310-822-6161; E-mail: RBoudreauMDJD@aol.com

Received date: July 15, 2016; Accepted date: July 19, 2016; Published date: July 20, 2016

Copyright: @ 2016 Boudreau R. This is an open-access article distributed under the terms of the Creative Commons Attribution License, which permits unrestricted use, distribution, and reproduction in any medium, provided the original author and source are credited

\section{Editorial}

Any person who has ever conducted research in the field of science recognizes how important it is to explore the research of other authors. Previous studies in science provide the foundation for new and emerging research that extends the body of existing knowledge. Citing previous studies places research in a scientific context, relates the rationale for a research study, and shapes an understanding of the science behind a new idea or hypothesis. Not every source cited in a research study supports the premise of the study; sometimes research is presented to demonstrate views that challenge a research premise to provide a starting point for a particular argument. In each case, citing sources in scientific studies is an essential part of this type of academic research. The foundation for any scientific research paper is the correct and adequate referencing of all of the materials that informed the research.

The referencing style outlined in this article is described as an "Author/Date" style that was adapted by the Council of Biology Editors in its final form in 1994. This article also includes information on the citing and documenting of government reports [1], and referencing for internet sources [2], as well as information related to paraphrasing and referencing of research in science [3-5].

\section{Using References in Your Scientific Research Papers}

You must cite all of the sources that you used in writing your own scientific research. Sources that need to be cited can include books, journal articles, newspaper articles, internet sites, blogs, email correspondence, and podcasts. Regardless of the type of source material, it is essential that you give credit to the author of information you've derived from another source.

This means that you must acknowledge the name of the author and provide a corresponding source in your reference page for each piece of existing information you use in your scientific research. Follow these four essential rules:

If you didn't know the information before you started your research, you need to cite the source.

If you use data from other sources, even if you use it in a different format (creating a table or using it to create comparisons), you need to cite the sources of the original data.

If you use ideas or theories presented by others, you need to cite the original source.

You need to cite the sources of information even if you put that information into your own words.
In determining what type of format is necessary, it is important to identify whether you are paraphrasing materials from another author or quoting that author directly.

\section{Paraphrasing vs. Quoting}

Knowing the difference between paraphrasing and quoting and how they are used can help you in your research process and when you turn your research into your own writing. Paraphrasing is the process of reading the ideas of others and then rewriting those ideas, in your own words, citing the original author, usually at the end of the paraphrase. Quoting involves the use of direct statements, placed in quotation marks, from an authoring individual. Quotes should only be used when it is essential that the exact wording of the author appear in your work. For the most part, any use of research should involve paraphrasing except for rare exceptions when direct quotes are essential to maintaining meaning.

Whether quoting directly or paraphrasing, you need to be sure to properly cite the material. Here are some important tips:

If you use more than three consecutive words from another author's writing, you need to put those words in quotes and cite using the author's last name, date, and page number.

Every sentence of information you paraphrase from another author should be cited.

Large amounts of quoted material, even if cited properly, are not appropriate in scientific research. You should be integrating small amounts of quoted material (quoted because it is essential to meaning) along with a large body of paraphrased material that shows your understanding of the content and its application to your topic.

If you do use larger quotes (more than a full line of text), present the quote in a block format, indented five spaces on each side and single spaced, in order to identify the larger quote in the text of your paper.

In creating effective use of paraphrasing and quotes, you must use appropriate in-text citations.

\section{Your In-Text Citations}

In-text citations take the place of footnotes and other citation styles based on the CBE's (1994) citation style [6]. The in-text citations used in scientific research are in Name/Date format and so the author's last name and the date of publication appear in each sentence attributable to another author. There are three basic ways of doing this:

1. Mention the author and cite the date after the authors name for any paraphrased material. For example:

Mann (2012) argued that the problem of creating a political basis for science is that the true data gets muddled in the debate. 
Page 2 of 3

2. Provide paraphrased information from the author and then cite the author at the end of the sentence. For example:

The National Academy of Sciences assessed the research and validated the research team's findings (Mann 2012).

3. Provide a direct quote by the author, based on the belief that the language of the quote is essential to its meaning.

"The fossil fuel industry is happy to fund those who attack our work" (Mann 2001, pp. 1).

Or

Mann stated: "The fossil fuel industry is happy to fund those who attack our work" (pp. 1).

Each of these examples identifies the last name of the author, the date of the publication, and indicates if the information was paraphrased (no quotation marks) or directly quoted (quotation marks). Page numbers are only needed for direct quotes. For every new author cited in a research paper, it is essential to have a correctly formatted reference that appears in the reference page at the end of the document.

\section{Formatting Your References}

Your reference list should appear at the end of your document and should include all of the resources that were cited in your paper. If you have additional sources that helped to inform your research search, but from which you did not derive any unique materials, these can be included in a separate reference page called: "Additional readings." The reference page should only include sources that are actually cited in the paper.

If you have more than one reference page entry by the same author, the entries should appear in descending order, with the most recent paper appearing first. If you have more than one source by the same author in the same year, distinguish these sources using by appending letters: a, b, c etc. For example, if Mann is the author of multiple sources that were created in 2012, Allen's first source would be noted as 2012a, the second $2012 \mathrm{~b}$, etc. and these letters would appear in the intext citation as well as in the reference page entry.

The following is a guide to the most common forms of references required for scientific research. For additional types of references, see Knisely [3] or McMillan [4].

\section{Books}

\section{Single Author}

Author, A., Year of publication, Title of Work: Capital Letters also for Subtitle, Publisher: Location.

McMillan, V. 2012, Writing Papers in the Biological Sciences, Bedford/St. Martin's, Boston.

\section{Multiple Authors}

Harnack, A., Kleppinger, E. 2000, Online! A Reference Guide to Using Internet Sources, Bedford/St. Martin's Press, New York.

\section{Articles or Chapters in Books}

Author, A. and Author, B., Year of publication, Title of Chapter, in A Editor and B. Editor (Eds.), Title of Book, Publisher: Location, pages of chapter.
Jones, B., 2014, The Central Nervous System, in B. Jones and F. Hartmouth (Eds.). Essential Anatomy, Norton: New York, pp. 451-466.

\section{Periodicals}

Author, A. and Author, B., Year of publication, Title of article, Title of Periodical, v. (volume number), p. pages.

Iribarren, C., Karter, A., Go, A., Ferrara, A., Liu, J., Sidney, S., and Selby, J., 2010, Glycemic control and heart failure among patients with diabetes, Circulation, v. 103, pp. 2668-2673.

For an online periodical without page numbers, use this format:

Author, A. and Author, B., Year, Title of article, Title of Periodical, v. (volume number), web address.

Iribarren, C., Karter, A., Go, A., Ferrara, A., Liu, J., Sidney, S., and Selby, J., 2010, Glycemic control and heart failure among patients with diabetes, Circulation, v. 103, http://www.someaddress.com/full/url/.

\section{Electronic Sources}

Author, A. and Author, B., Year of publication, Title of article, web site (date accessed).

Huff, F., 2012, Findings of the National Geological Survey, http:// www.someaddress.com/full/url/ (July 1, 2016).

\section{OR}

Authoring Agency, Year of publication, Title of article, web site (date accessed).

United States Department of Housing and Urban Development. (2008). Indiana income limits, http://www.huduser.org/Datasets/IL/ IL08/in_fy2008.pdf (July 1, 2016).

\section{FAQs}

1) I have some books that I read that helped me place my research in context, but I didn't cite them in my paper. Do I include those in my "References" page?

Answer: You do not include them in your reference page unless you used ideas or content and cited them in the text of your research. You can, however, include them in a supplementary "Additional Readings" list.

2) What if I do not has all of the information required (e.g. a web page without a date or a journal without a volume number)?

Answer: Put in the information that you do have and leave the other information out. You can use n.d. if you are missing the date of a website or publication. Use as much information as you can locate on your sources and leave the rest of the information blank. For example:

United States Department of Housing and Urban Development (nd). Indiana income limits, http://www.huduser.org/Datasets/IL/IL08/ in_fy2008.pdf (July 1, 2016).

3) If I put an in-text citation at the beginning of a paragraph, do I really need to put a citation at the end of each sentence that is attributable to that author in the same paragraph? What about in subsequent paragraphs?

Answer: You need to cite every sentence that is attributable to another author. You can cite it in a number of different ways (mention the author in the sentence, cite at the end of the sentence, use a direct 
Page 3 of 3

quote) in order to make the material more readable, but you need to cite the author each time you use the information in a paragraph or the research document as a whole.

4) What about using other citation styles like APA, MLA, or CSA?

Answer: The CBE format is used for scientific research by many in the scientific community, but other formats are also recognizable. For example, science in health fields often uses APA (American Psychological Association) format. Use the format that has been identified as preferable by your institution or governing organization.

\section{References}

1. Hansen WR (1991) Suggestions to authors of reports of the United States geological survey. (7th edn.) US government printing office, Washington DC, USA.
2. Harnack A, Kleppinger E (2000) Online! A reference guide to using internet sources. Bedford/St. Martin's press, New York, USA.

3. Knisely K (2013) A student handbook for writing in biology. Sinauer associates, Sunderland, MA.

4. McMillan V (2012) Writing papers in the biological sciences. Bedford/St. Martin's, Boston.

5. Pechenik J (2013) A short guide to writing about biology. Pearson, Boston, USA.

6. Council of Biology Editors (1994) Scientific Style and Format: The CBE Manual for Authors, Editors, and Publishers. (6th edn.) Cambridge University Press, New York. 